\title{
POLÍTICAS, PRÁTICAS E PRODUÇÃO DO \\ CONHECIMENTO NO GTT 12 - INÇLUSÃO E DIFERENÇA: PARRÉSIA, AFORISMOS, POESIAS
}

\section{Cláudio Marques Mandarino}

Universidade do Vale do Rio dos Sinos, Sao Leopoldo, Rio Grande do Sul, Brasil.

\begin{abstract}
Resumo
Este ensaio tem por objetivo dialogar com a experiência advinda da passagem pelo GTT 12 - Inclusão e Diferença do Colégio Brasileiro de Ciências do Esporte. Nesse sentido, apresenta uma análise sobre alguns caminhos docentes e acadêmicos possíveis de serem percorridos. Munido de aforismos e poesias, este trabalho se aproxima de um exercício parresiástico (fala franca) para fazer um debate com as tensões que circulam no referido grupo temático de trabalho. A tensão é entendida pela sua potência enquanto possibilidade de permitir um movimento que desacomoda e que não é permanente.
\end{abstract}

Palavras chave: Inclusão e Diferença. Parrésia. Poesias. Aforismos.

\section{Introdução}

\begin{abstract}
Em outras palavras, não há como evitar essas tensões mesmo nas propostas mais "democráticas", nas que se fala em "ensinar a pensar" ou em "aprender a aprender", há sempre forças, espaços, potências do pensamento em colisão para que haja filosofia - e pensá-las é uma exigência para um educador interessado em propiciar espaços de pensamento potentes, livres e abertos à transformação de si e dos outros. (KOHAN, 2009, p. 11)
\end{abstract}

Seguindo o pensamento do autor da epígrafe, destaco que, entre a mudança e a permanência, entre a pedagogia e a expertise psicológica ${ }^{1}$, entre a ousadia e a resignação, entre a presença e a ausência, entre a aceitação

Nikolas Rose (2011, p. 116) explica que a conduta humana tornou-se uma tarefa psicológica. "Experts em psicologia, vocabulários psicológicos, avaliações psicológicas e técnicas psicológicas fizeram-se indispensáveis nos locais de trabalho e no mercado de trabalho, no processo eleitoral e nos assuntos da política, na vida familiar e na sexualidade, na pedagogia e na educação das crianças, no aparato das leis e punições e no complexo medicina/bem-estar social".

Pensar a Prática, Goiânia, v. 17, n. 3, p. 893-910, jul./set. 2014 
e a refutação, e entre o estar presente e o seu afastamento, são estas tensões que me animam a sair daqui diferente de como entrei.

E foi com o ânimo acadêmico, reflexivo e literário que este ensaio foi escrito para participar da mesa que tratou sobre os temas da política, das práticas e da produção do conhecimento vinculados ao Grupo de Trabalho Temático 12 - Inclusão e Diferença (GTT 12 - ID), por ocasião do XVIII Congresso Brasileiro de Ciências do Esporte e do V Congresso Internacional de Ciências do Esporte (Conbrace e Conice), ocorridos no ano 2013 na cidade de Brasília-DF.

Os referidos eventos são promovidos pelo Colégio Brasileiro de Ciências do Esporte e ocorrem a cada dois anos. Tendo como pauta os grandes megaeventos esportivos da atualidade, foram tematizados os impactos relacionados à identidade profissional e à produção do conhecimento num tempo em que a lógica produtivista não deve comprometer o caráter crítico e as tensões presentes no campo acadêmico. Sendo uma entidade científica, o CBCE congrega pesquisadores (profissionais e estudantes) de diferentes campos do conhecimento tendo como objetivos ${ }^{2}$ :

\begin{abstract}
a. Promover e incrementar os estudos e pesquisas relacionadas à área acadêmica Educação Física; b. Veicular o conhecimento produzido na área da Educação Física por meio da publicação de periódicos, da promoção de reuniões científicas e outras iniciativas de distintas ordens; $c$. Manter intercâmbio com entidades nacionais e internacionais com interesses em áreas afins e de caráter similar; d. Posicionar-se em questões de políticas referentes às áreas com as quais guarda relação de estudo e produção de conhecimento. (CBCE, 2006).
\end{abstract}

O CBCE é composto por 13 Grupos de Trabalho Temáticos que são instâncias organizativas de polos aglutinadores de pesquisadores, polos de reflexão, produção e difusão do conhecimento e sistematizadores da produção do conhecimento com vistas à parametrização das ações políticas das instâncias executivas do CBCE (Grupos de Trabalho Temáticos) ${ }^{3}$.

Nesse sentido, o GTT 12 - ID, composto por pesquisadores de diversas universidades, vinculados a campos do conhecimento que têm como interesse a inclusão e a diferença, passou pela transição da mudança do seu

${ }_{3} \frac{\text { http://www.cbce.org.br/cbce-estatuto.php). Acesso em: } 15.03 .2014 .}{\text { http://www.cbce.org.br/gtt.php. Acesso em: 15.03.2014 }}$

Pensar a Prática, Goiânia, v. 17, n. 3, p. 893-910, jul./set. 2014 
nome e ementa ${ }^{4}$ a partir 2009. Face à demanda relacionada às políticas de inclusão escolar, traz no seu interior pesquisadores que têm desenvolvido pesquisas relacionadas ao tema da inclusão. Em função disso, no Conbrace e no Conice de 2013, também ocorreu uma mesa temática composta pelo GTT - Escola e pelo GTT - Movimentos Sociais, tendo como tema a "Educação Escolar: diferenças, formação e prática docente". Essas demandas têm levado a colocar em debate a formação acadêmica em diferentes âmbitos de atuação do professor de Educação Física em relação à inclusão escolar.

Considerando os diferentes olhares relacionados à inclusão escolar e sem pretender trazer aqui uma visão consensual, apresento um lugar onde tenho me filiado para debater este tema, seguindo a compreensão de Lopes (2007), que explica ser a inclusão uma verdade da nossa época que está presente pela força da lei, pois muitos documentos, leis, decretos, encontros têm acenado para o processo inclusivo.

A isso Lopes e Fabris (2013, p. 16) posicionam como o imperativo de Estado, em que a sua estratégia faz operar o princípio de educação para todos, e comentam que, "independentemente de como ela é tomada, o que nos interessa é recorrência com que é referida tanto no campo da educação quanto no campo das ciências econômicas, sociais e políticas". Nesse sentido, as autoras nos convidam a pensar e problematizar a inclusão, considerando que fiquemos

[...] não somente mobilizados pela obediência (pura e simples) à lei, nem pela militância disciplinar (que tem na ordem o seu princípio regulador), nem pelo caráter salvacionista (fortemente produzido pelo humanismo e pelas raízes judaico-cristãs que carregam) e nem pela necessidade de mudanças emergentes das condições do país frente às necessidades do presente. Queremos pensá-la pela vontade de articular a experiência de viver o coletivo e de ter nossas condutas dirigidas de forma mais coerente com a noção de direito, nesse caso, à educação para todos. (LOPES; FABRIS, 2013, p. 15).

\footnotetext{
$4 \quad$ Acolhe trabalhos que tratam de um campo de conhecimento das Ciências Sociais, Humanas e Biológicas na Sociedade, Escola e Educação Física entendendo as diferenças em seus múltiplos sentidos identitários de pessoas posicionadas nas suas classes sociais, econômicas, culturais, de raça/etnia, gênero, religiosidade, com necessidades especiais, etc, e que produzem e são produzidas na inclusão/exclusão.
}

Pensar a Prática, Goiânia, v. 17, n. 3, p. 893-910, jul./set. 2014 
Ao comentar dessa forma, as autoras esclarecem a inclusão como sendo uma verdade que produz efeitos reais a partir dos seus discursos para distintos sujeitos. E esse movimento de quem está envolvido com o tema nos oferece uma experiência que "nos faz entender aquilo que nos tornamos, aquilo pelo que lutamos e aquilo que acreditamos no presente" (2013, p. 19). Nessa linha de pensamento, Lopes e Rech (2013, p. 212) nos apresentam a "noção da inclusão como imperativo", que implica uma imposição em que todas as instituições ou órgãos públicos dela tenham que declinar.

Ao acenar que a inclusão tem reduzido as inúmeras exclusões aos discriminados historicamente e nomeando os sujeitos que se enquadram nesses processos por razões econômicas, de gênero, raça-etnia, deficiências físicas, cognitivas, sensoriais, entre outras, negadas e silenciadas pelo Estado, Lopes e Fabris (2013, p. 21) estabelecem um diálogo direto com uma direção que o GTT 12 - ID assumiu na sua ementa em relação às políticas, às práticas e à produção do conhecimento. Nesse sentido, temos a oportunidade de direcionarmos um olhar a nós mesmos sobre como temos nos construído e nos transformado a partir da inclusão escolar e pela vinculação ao GTT 12 - ID.

Feitos esses primeiros esclarecimentos, que contextualizam o trabalho e que começam a situar o lugar de onde estarei falando, faço a seguinte pergunta: Como estamos lidando com a nossa própria experiência pessoal e profissional, quando falamos de inclusão e diferença?

Com essa pergunta, procuro mostrar que a passagem pelo GTT 12 ID está aberta para um diálogo sobre as mudanças inerentes ao seu contexto acadêmico e científico. Porém, como esclarece Walter Omar Kohan ${ }^{5}$, o questionamento, para ser potente, deve suscitar outras perguntas. Com essa pergunta está presente aquilo que, numa carta, Foucault (2006a) identifica como o sentido duplo e a missiva: o sentido duplo porque, ao mesmo tempo em que inicio questionando a quem lê, identifico que ela também pergunta como eu me relaciono com essa questão; e é uma missiva no momento em que se destina para quem a lê e se sente provocado a fazer tal incursão.

Dessa forma, pretendo me aproximar do tema deste ensaio que trata da prática, da política e da produção do conhecimento. Os caminhos escolhidos

\footnotetext{
Na formação para professores da Unisinos, no ano de 2011/1, o professor Walter Omar Kohan apresentou o seguinte título da palestra: O que deve saber um professor deste tempo para alunos deste tempo? No decorrer da sua explanação, comentou que esta era uma pergunta que deveria suscitar outras perguntas para quem estivesse presente no evento, ou seja, era uma pergunta que tinha feito para si mesmo, a partir de questões que diziam respeito às suas reflexões. Nesse sentido, a ideia não era de trazer uma resposta para quem estava assistindo à formação, mas sim que ela permitisse que os/as professores/as elaborassem outras perguntas, para si mesmos.
}

Pensar a Prática, Goiânia, v. 17, n. 3, p. 893-910, jul./set. 2014 
aqui permitem olhar para diferentes paisagens dialógicas. Uma das vias tem no seu entorno imagens que mostram a política e a prática do referido grupo de trabalho temático e suas interfaces com temas que envolvem movimentos de resistência representados pelos temas em foco. Na outra paisagem, está presente a produção de conhecimento como algo que surge a partir da prática direcionada à política do GTT 12 - ID.

Entre imagens da política, da prática e da produção do conhecimento, este caminho encontrará algumas poesias e aforismos que se misturam nos cenários das experiências que se relacionam com o tema proposto. A poesia aqui tem sido um instrumento pedagógico que tem acompanhado as diferentes experiências relacionadas ao meu fazer docente nos últimos anos $^{6}$. Elas remetem à minha própria experiência de mim comigo mesmo (LARROSA, 1994), enquanto pesquisador, professor universitário e professor de escola pública que faz uma narrativa de si e que, como destaca Foucault (2010, p. 289), ao tratar da noção de experiência como sendo "qualquer coisa de que se sai transformado", não sai o mesmo depois que termina um livro ou um texto. E não estaria equivocado ao dizer que as práticas cotidianas de resistência e movimentos políticos tenham esse mesmo efeito.

Já os aforismos ${ }^{7}$ trazem outras combinações a esta paisagem, sendo percebidos como flechas nietzschianas prontas a mirar nas certezas e crenças enraizadas no nosso tempo. Nietzsche (apud BACKES, 2010, p. 14) comenta sobre o aforismo, explicando ser ele "a sentença, nos quais pela primeira vez sou mestre entre os alemães, são formas de 'eternidade': a minha ambição é dizer em dez frases o que outro qualquer diz num livro -, o que outro qualquer 'não' diz nem num livro inteiro".

Portanto, no objetivo de dialogar com a experiência individual advinda dos termos inclusão e diferença no interior do referido grupo de trabalho temático, o ensaio abordará por primeiro a política e as práticas, e posteriormente a produção do conhecimento. Por último, serão feitos os encaminhamentos com algumas proposições sobre o que foi desenvolvido no decorrer deste trabalho.

$6 \quad$ Estou me referindo à disciplina de Estratégias de Ensino e Inclusão, na qual os acadêmicos têm a tarefa de elaborar uma poesia sobre os conteúdos desenvolvidos e nas experiências na Educação Física escolar (publicadas em periódicos desta área de conhecimento) em escolas públicas do município de Porto Alegre.

7 Abbagnano (2003, p. 21) destaca que o aforismo é "uma proposição que exprime de maneira sucinta uma verdade, uma regra ou uma máxima concernente à vida prática".

Pensar a Prática, Goiânia, v. 17, n. 3, p. 893-910, jul./set. 2014 


\title{
A política e a prática da parrésia no GTT 12 - Inclusão e Diferença
}

"O que temos escrito sobre aquilo que transformou alguma coisa do nosso pensamento? Opa! Esta é uma pergunta para quem permite ser desacomodado." (O autor, 2013).

Ao iniciar esta seção com o primeiro aforismo, faço o seguinte desdobramento da pergunta apresentada: Os integrantes do GTT 12 - ID estão saindo transformados dessa experiência de participar, expor trabalhos acadêmicos a partir de um olhar da inclusão e diferença dentro de uma perspectiva pedagógica?

No GTT 12 - ID, construímos uma história acadêmica de nós mesmos. Histórias que narram uma identidade sobre nós mesmos e as mudanças ou não do nosso pensamento e da nossa maneira de interpretar o mundo. Esse mundo que é líquido (BAUMAN, 2001), múltiplo, incerto, com fronteiras borradas, includente e excludente, individual e coletivo etc. Nesse duplo em que estão presentes a prática moral, a ética, a docência, enfim, o espaço acadêmico produz uma experiência que nos transforma enquanto educadores e pesquisadores, diferentes de quando começamos a transitar por ele.

Ao fazer esta escolha política, em que a direção a ser tomada é menos confortável, segura, permanente e resignada e mais direta e franca, ela se aproxima do exercício da noção de parrésia. O dizer-verdadeiro entra em jogo numa relação entre o sujeito e a verdade, o sujeito como objeto do seu próprio conhecimento:

\begin{abstract}
A parrésia é, portanto, em duas palavras, a coragem da verdade naquele que fala e assume o risco de dizer, a despeito de tudo, toda a verdade que pensa, mas é também a coragem do interlocutor que aceita receber como verdadeira a verdade ferina que ouve. (FOUCUAULT, 2011, p. 13).
\end{abstract}

Entre o debate sobre o GTT 12 - ID e o aforismo, encontram-se o pesquisador e a sua vontade de exercitar a parrésia, o dizer-verdadeiro, a fala franca. Mas fazer o exercício da fala franca, o dizer-verdadeiro, neste ensaio, através de perguntas, reflexões, aforismos e poesias, é apenas uma estratégia para suscitar o debate que cada um de nós pode se permitir fazer.

Portanto, abro aqui duas janelas para observar o horizonte deste ensaio: a primeira, mostrando as implicações de cunho acadêmico que a parrésia traz na sua potencialidade; e a segunda, como isso produz o próprio pensamento e as decisões para esse investimento.

Pensar a Prática, Goiânia, v. 17, n. 3, p. 893-910, jul./set. 2014 
Não se trata, de modo algum, de analisar quais são as formas do discurso tais como ele é reconhecido como verdadeiro, mas sim, sob que forma, em seu ato de dizer a verdade, o indivíduo se constitui e é constituído pelos outros como sujeito que pronuncia um discurso de verdade. (FOUCAULT, 2011, p. 4).

A aleturgia presente no discurso, daquilo que é verdadeiro, pode ser refletida poeticamente da seguinte forma:

\begin{abstract}
Aleturgia do que é vero/ com ou sem miopia/ discurso daquilo que sentia/ constituído na experiência que vivia/ o corpo e a subjetividade se produzia/ conhecendo a sua própria verdade/ estudante em formação/ pensamento em liberdade. (O autor, 2013).
\end{abstract}

Fazer, nesta poesia, o exercício da parrésia a partir de verdades que necessitam ser ditas e desveladas, tais como a invenção do termo adaptado ${ }^{8}$ que segue uma orientação categórica e classificatória no melhor estilo aristotélico e moderno, é um movimento pedagógico e ético de um cuidado de si que potencializa o diálogo com a nossa própria experiência. Para onde vamos, então? Resgato aqui uma pergunta parecida com a imagem da fotógrafa Paola Pivi, ao mostrar um asno à deriva dentro de um bote e que leva como título: "Para onde vai este asno?"

8 O questionamento do termo "adaptado" foi apresentado no XV Conbrace e II Conice ocorrido em Recife no ano de 2007, tendo como título: Educação Física adaptada: território de práticas messiânicas.

Pensar a Prática, Goiânia, v. 17, n. 3, p. 893-910, jul./set. 2014 


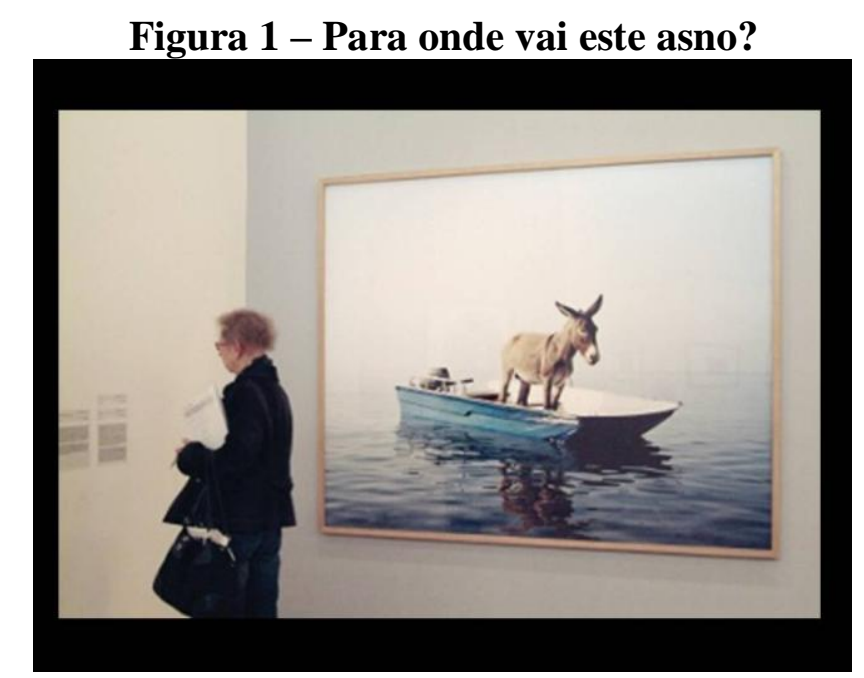

Fonte: Paola Pivi - Centro Pompidou (Paris, 2003)

Temos ali um olhar resignado que aceita o devir do mundo como ele é e que se deixa levar, um mundo onde as metas se perderam, os objetivos estão confusos: para onde vamos? Também podemos pensar na potência da incerteza, do futuro do porvir etc. Porém, como interpreta Larrosa (2008, p. 199) sobre o livro Confissões, de Jean Jacques Rousseau, como uma literatura que não pode mais regressar, destacando: "Su viaje se convierte, más bien en una errancia infinita en la que no hay meta a la que llegar ni posibilidad de vuelta al punto de partida".

Qual é a meta do GTT 12 - ID? Entre o para todos e o cada um, como demarcou Linhares ${ }^{9}$, na mesa do XVII Congresso Brasileiro de Ciências do Esporte e IV Congresso Internacional de Ciências do Esporte, fazendo o questionamento de como se fazer essa conciliação. Abrem-se duas paisagens a se observar: de um lado, existe uma possibilidade de enfraquecer os termos, pois a inclusão é para todos, assim, tudo cabe dentro dela, e a diferença é de cada um (todos são diferentes); por outro lado, os termos podem se potencializar, se entendermos estar diante de uma abertura, quando a nossa reflexão se volta para a "inclusão de cada um e a diferença de todos" dentro das condições de possibilidade do nosso tempo.

A produção de sentidos da inclusão de cada um como um movimento de resistência ao assujeitamento (FOUCAULT, 2006b) e a capacidade da diferença em se multiplicar (SILVA, 2002). Nesta última imagem, a relação

9 A produção acadêmico-científica do GTT Inclusão e Diferença no 15 anos do CBCE. 2011. Palestra apresentada no GTT 12 - Inclusão e Diferença no XVII Conbrace e no IV Conice. Porto Alegre, 2011. Não publicado.

Pensar a Prática, Goiânia, v. 17, n. 3, p. 893-910, jul./set. 2014 
de si consigo mesmo se torna mais potente e permite fazer um deslocamento das identidades fixas e permanentes. E nela faço esta escolha política e acadêmica para seguir o caminho e permitir esta experiência.

O que estou valorizando neste debate, portanto, é a nossa transformação de indivíduos, em que passamos a utilizar um pensamento acadêmico científico para se interpretar, autointerpretar e se modificar a partir dessa experiência. Nessa trajetória, é possível contar que as práticas pedagógicas que tenho e que temos experimentado nos últimos anos têm sido atravessadas por esses campos de saber, dando novas formas a partir de uma repetição e da diferença (DELEUZE, 2006). Sou o mesmo transformado em outro, sem negar a mim mesmo, mas saindo dessa experiência diferente daquilo que eu era antes.

O GTT 12 - ID, entendido por esse prisma, apresenta a possibilidade da abertura, o futuro do porvir e não o seu devir. No dever ser, ele (e os seus membros) são capturados pelo assujeitamento que se constrói através de suas práticas discursivas e não discursivas. No porvir, o acontecimento é o governo do presente, em que cada indivíduo tem a possibilidade se construir nele, fazendo dele a sua própria potência.

O aspecto pedagógico que está presente neste grupo temático está pautado por uma ética que expõe os diferentes modos de assujeitamento (FOUCAULT, 2006b) produzidos pela cientificidade. Enquanto uma pedagogia das patologias, daquilo que é visível e dizível e que está colocado em relação ao verdadeiro e o falso, produz uma subjetivação sobre sujeitos de uma determinada prática, aprisionando o louco e o deficiente.

Ao se narrar/escrever sobre o louco se reforça a racionalidade, ao se narrar/escrever sobre a criança se produz a infância, ao se narrar/escrever sobre o deficiente se produz a diferença, ao se narrar/escrever sobre a norma se produz a anormalidade (os anormais), enfim, ao se narrar/escrever sobre o outro se reforça o mesmo.

\begin{abstract}
A partir de que práticas, através de que tipos de discursos se tentou dizer a verdade sobre o sujeito louco ou sobre o sujeito delinquente? A partir de que práticas discursivas se constituiu, como objeto de saber possível, o sujeito falante, o sujeito trabalhante, o sujeito vivente? (FOUCAULT, 2011, p. 5).
\end{abstract}

Tendo o conteúdo dessa citação como referência, faço a seguinte pergunta: A partir de que discursos o GTT 12 - ID tem produzido uma verdade sobre os sujeitos ali narrados como integrantes de um desporto adapta$d o$, de uma captura da inclusão? Por outro lado, podemos perceber uma ou-

Pensar a Prática, Goiânia, v. 17, n. 3, p. 893-910, jul./set. 2014 
tra pedagogia, que produz/narra/escreve outras relações consigo mesmo (FOUCAULT, 2006b). Estamos assistindo, vivendo, participando de diferentes formas de resistência a partir de movimentos que antes não encontravam uma potencialidade para nos desacomodar. As tensões em relação a raça/etnia, gênero, homofobia, identidade, diferença, inclusão, entre outros, estão aí para nos afetar e exigir de todos/as um posicionamento.

Isso acena condições de possibilidade para fazermos outras perguntas: Como as nossas práticas acadêmicas têm nos colocado diante de uma moral em que passamos a fazer uma relação consigo mesmo? Estamos escrevendo as mesmas coisas de antes? Estamos lendo os mesmos autores? Estamos experimentando outras pedagogias? Estamos estabelecendo uma diferença naquilo que repetimos? Será que os nossos trabalhos narram as mudanças que temos passado? Estas, portanto, são outras perguntas que passam pela política, pela prática e pela produção do conhecimento na/da inclusão e diferença. Com essas perguntas se afasta a possibilidade de ficar à deriva, como o asno de Paola Pivi.

\section{Produção do conhecimento no GTT 12 - Inclusão e Diferença}

"E a diferença dentro da diferença? Existe melhor pergunta para travar o nosso pensamento? Não seria isto um aprisionamento teórico?" (O autor, 2013)

Na produção do conhecimento no GTT 12 - ID, o debate sobre as posições que os sujeitos ocupam nas pesquisas apresentadas mostra um lugar em que a diferença necessita ser desvelada. É recorrente associar ao termo diferença o sentido da diversidade, ou então reforçar os sentidos dos binarismos a partir dos pares normal/anormal, incluído/excluído, dentro/fora, ou seja, olhar mais para a patologia, a falta, a deficiência, a alteridade - o ser outro -, e menos para os mecanismos que os produziram enquanto algo que permite a existência do primeiro termo, o termo que estabelece a referência, que reforça o "mesmo".

Percebendo isso, uma lógica de compreensão que emerge parte da ideia de que na inclusão estaremos incluindo, reforçando somente aqueles que carregam consigo a marca da exclusão, do preconceito, do estranhamento, do silenciamento, como nos alertam Lopes e Fabris (2013). Ao iniciar esta seção com o aforismo, procuro questionar um tipo de retórica que busca anular a potencialidade da palavra diferença.

Nessa operação, se aceita que todos são diferentes, porém existem diferenças que se afastam das normas estabelecidas por uma diferença que está sob a égide do par normal e anormal. Considero pertinente questionar a celebração de diferença, contudo não precisamos fazer dela a nossa impossi-

Pensar a Prática, Goiânia, v. 17, n. 3, p. 893-910, jul./set. 2014 
bilidade para nos abrirmos ao debate. Poderíamos, quem sabe, pensar na abertura que a identidade, a diferença e a inclusão nos permitem a partir desta poesia que assume a forma de uma fita de Möbius ${ }^{10}$ :

Fita de Möbius.

As identidades repetidas

IIIIIIIIIIII/.as diferenças iguais

/I/I/I////I//////........as inclusões excluídas

I/II/I/I/I/I/I/I/...............as identidades produzidas

IIIIIIIIIIIIIIII as diferenças excluídas

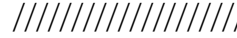
as inclusões iguais

/II/II/I/II/I. as identidades excluídas

//III/I/I/I/II///as diferenças produzidas

//I/I/I/I/I/I/I/////as inclusões repetidas

I/I/I/I////as//identidades//iguais

as///diferenças///repetidas

as//inclusões//produzidas

as identidades//I//I/I//I/I//I

as diferenças .$/ / / / / / / / / / / / / / / 1$

as inclusões $1 / / / / / / / / / / / 1 / 1$

as repetidas diferenças. $. / / / / I / / / / / / / 1$

as diferentes identidades ./IIIIIIIIIIIII

as identidades repetidas.....///I/I//I///I//I

as diferenças iguais......//I///I/I////I

as inclusões excluídas..//III/

e o a priori continual/////

Esta é uma poesia em que a composição das palavras mostra diferentes produções discursivas, mas que se pretende levar ao seguinte aforismo: poesias da diferença e diferença nas poesias. A poesia potencializando a diferença pela diferença. Dar o sentido de multiplicidade, replicação, resistência, desobediência à diferença é percebermos que há algo a mais para compreender dentro desse mecanismo. Para que se desloque a compreensão da diferença como uma oposição da normalidade, uma contradição presente na dialética, poderíamos procurar na diferença o sentido de uma multiplicidade, e sobre isso Michel Foucault esclarece:

10 A fita de Möbius representa o oito do infinito e pode ser feita a partir de uma fita em que se faz uma dobra de 180 graus, unindo as suas extremidades e dando origem a um caminho que se repete.

Pensar a Prática, Goiânia, v. 17, n. 3, p. 893-910, jul./set. 2014 
Para liberar a diferença é preciso um pensamento sem contradição, sem dialética, sem negação: um pensamento que diga sim à divergência; um pensamento afirmativo cujo instrumento é a disjunção: um pensamento do múltiplo - da multiplicidade dispersa e nômade que não é limitada nem confinada pelas imposições do mesmo: um pensamento que não obedece ao modelo escolar (que traga a resposta pronta), mas que se dedica a insolúveis problemas, ou seja, a uma multiplicidade de pontos notáveis que se desloca a medida que se distinguem as suas condições e que insiste, subsiste em um jogo de repetições. (2008, p. 245-246).

Lopes (2007, p. 21), a seguir nesta linha de pensamento da diferença, porém posicionando-a na escola inclusiva e alertando sobre o seu apagamento a partir dos binarismos, destaca que é necessário pensar também a diferença no campo político das experiências, inscrito na história e afastandose de um entendimento de Estado indesejável ou impróprio, e comenta: "Sendo uma condição necessária para a própria ideia de inclusão, a diferença surge como possibilidade de resistência a politicas excludentes e práticas classificatórias e hierárquicas".

Como a autora comenta, essa é uma perturbação da ordem. Para que possamos ir além da perturbação da ordem, faz-se necessário que a diferença esteja noutro sentido, mostrando a sua potencialidade de não se acomodar, ao ser capturada por essas classificações, mas aparecer de outra forma, ainda não categorizada, mostrando o quando ela é uma diferença em si mesma e não algo que emerge a partir de um jogo de contradições.

Enquanto as pesquisas apresentadas no GTT 12 - ID estiverem pautadas por esse olhar em relação à diferença, elas permitirão que o campo do olhar da diversidade, deixem de valorizar um sujeito do porvir, um sujeito ainda não capturado, não previsto. Sendo assim, se faz necessário escrever outras histórias, histórias que passem pela própria formação de si, pelas próprias práticas pedagógicas que nos transformam e nos mostram se somos professores de sujeitos do devir ou professores de sujeitos do devir.

\section{Proposições ao GTT 12 - Inclusão e Diferença}

Organizar uma narrativa, uma história de si, e depois repeti-la novamente, nos mesmos lugares, em tempos e espaços diferentes. Seria essa uma boa estratégia para aprender a refletir sobre uma prática pedagógica que quer conhecer a si mesma? (O autor, 2013)

Pensar a Prática, Goiânia, v. 17, n. 3, p. 893-910, jul./set. 2014 
Diante da prática, política e produção do conhecimento, encaminho proposições e resgato, nesta seção, alguns temas que foram recorrentes no ensaio para pensarmos em nossas próprias histórias de si e como temos nos tornado pesquisadores/as, professores/as, formadores/as. Parece ser um passo interessante para outros desdobramentos a serem dados ao GTT 12 - ID.

O GTT 12 - ID carrega consigo esse processo pedagógico em que aprendemos a dialogar com as experiências de si consigo mesmo a partir da narrativa de uma escrita de si. Michel Foucault explica a origem do seu projeto:

Meu problema é o de fazer eu mesmo - e de convidar os outros a fazerem comigo, por meio de um conteúdo histórico determinado - uma experiência daquilo que nós somos, daquilo que não é somente do nosso passado mas também do nosso presente, uma experiência da nossa modernidade de tal maneira que dela saímos transformados. (FOUCAULT apud REVEL, 2005, p. 48).

Ou então:

Tratava-se de ver de que maneira, nas sociedades ocidentais modernas, constituiu-se uma 'experiência' tal, que os indivíduos são levados a reconhecer-se como sujeitos de uma 'sexualidade' que abre para campos de conhecimento bastante diversos, e que se articula em um sistema de regras e coerções. O projeto era, portanto, o de uma história da sexualidade enquanto experiência, se entendermos por experiência a correlação, em uma cultura entre campos de saber, tipos de normatividade e formas de subjetividade [...] (FOUCAULT, 2006b, p. 10-11).

E quando se aprende a dialogar com as experiências de si consigo mesmo, dessa forma é possível, como já o fez este grupo temático, abandonar o seu próprio nome ${ }^{11}$ (Pessoas Portadoras de Necessidades Especiais) para dar sentido, como comenta o filósofo, a outros campos do saber, tipos de normatividade e formas de subjetividade. Abriu-se a possibilidade de um

\footnotetext{
11 O debate sobre a mudança do nome dentro do Grupo de Trabalho Temático pode ser lido no ensaio que trata da "Inclusão e Diferença: tensionamentos e debates na formação acadêmica", em: $<$ http://cbce.tempsite.ws/congressos/index.php/sulbrasileiro/vcsbce/paper/viewFile/2029/10 59>. Publicado em 2010.
}

Pensar a Prática, Goiânia, v. 17, n. 3, p. 893-910, jul./set. 2014 
porvir inatual, inaudito, intempestivo, ainda não capturado, que está à espera de outros aforismos, poesias e parrésias, que traga outros posicionamentos para a inclusão e a diferença e os/as pesquisadores/as que dela se nutrem.

As reflexões aforísticas e suas máximas permitiram o encontro da noção de parrésia com uma maneira de mostrar como é possível lidar com os temas da inclusão e da diferença a partir de um lugar pouco comum no âmbito acadêmico. O princípio pedagógico aí colocado se propõe a afetar o outro ao mesmo tempo em que é um documento de identidade do próprio autor, posicionando-se, mostrando quem ele é e onde se encontra o seu pensamento.

Os aforismos que foram apresentados aqui podem ser classificados dentro de uma categoria acadêmica, porque são elaborados a partir de uma relação direta com este contexto. Tiveram como objetivo ser provocadores e questionadores de muitas naturalizações que se configuram como verdades fechadas na formação docente. Eles devem ser lidos e relidos calmamente. É por isso que guardam uma relação muito íntima com o livro do filósofo Friedrich Nietzsche, Escritos sobre educação, em cuja apresentação o autor esclarece:

Este livro é destinado aos leitores calmos, aos homens que não foram ainda arrastados pela pressa vertiginosa da nossa época e que não experimentaram um prazer idólatra de se deixar esmagar por suas rodas - portanto, a bem poucos homens! Mas estes homens não podem já habituar-se a calcular o valor de cada coisa pelo tempo economizado ou pelo tempo perdido, eles têm "ainda tempo"; e lhes é ainda permitido, sem experimentar remorso, escolher e buscar as boas horas do dia e seus momentos fecundos e poderosos para meditar sobre o futuro da nossa cultura, eles têm o direito de acreditar que passaram seu dia de maneira digna e verdadeiramente útil, na meditatio generis futuri. (NIETZSCHE, 2009, p. 54-55).

Os aforismos e suas máximas permitiram refletir sobre como determinadas verdades estão presentes e expõem as tensões acadêmicas. Tensões que são inerentes à necessidade de um grupo que não deve se colocar diante de temas como identidade, deficiência, desporto adaptado, inclusão, diferença como algo a ser tratado de forma rápida, nem aceitar de forma naturalizada os discursos hegemônicos deste tempo. Faz-se necessário que tenhamos a calma para olharmos para os sentidos que são produzidos e que nos produzem para pensarmos na nossa formação e transformação nos rumos que temos dado ao GTT 12 - ID.

Pensar a Prática, Goiânia, v. 17, n. 3, p. 893-910, jul./set. 2014 
Nesse sentido, um interessante tipo de pesquisa sobre os trabalhos que foram apresentados pelos integrantes deste grupo temático - a partir do momento em que se chamava "pessoas portadoras de necessidades especiais" até este momento "inclusão e diferença" - poderia levar em consideração as transformações que se deram, desde os temas escolhidos, os tipos de pesquisa, os autores consultados, a intencionalidade de cada estudo até a linha de pensamento utilizada.

Penso que focar individualmente os autores e seus trabalhos permitirá fazer com que tracemos uma linha de mudanças, permanências, resistências etc. em relação à sua política, à prática e à produção do conhecimento. $\mathrm{O}$ interessante seria que isso fosse feito pelo próprio pesquisador, ou seja, fazendo uma narrativa de si, estabelecendo uma relação consigo mesmo e naquilo que o filósofo Sêneca já tinha refletido, que o educador deve aprender a instruir a si mesmo. Ao fazer esse exercício, o próprio pesquisador não se deixa ser refém de um discurso que o captura e o posiciona muitas vezes numa imanência, numa permanência. $\mathrm{O}$ valor pedagógico de uma narrativa de si permitirá mostrar como se estabeleceu uma relação a partir daquilo que o transformou num pesquisador diferente do que era antes.

\section{Considerações Finais}

Como último aforismo, escrevo: Organizar uma narrativa, uma história de si, relê-la, é uma boa estratégia para aprender a refletir sobre uma prática pedagógica que quer conhecer a si mesmo?

Entendo que estamos diante de uma grande oportunidade para trazermos, pedagógica e academicamente, um olhar para o Colégio Brasileiro de Ciências do Esporte sobre como essa tensão está presente no contexto escolar no que tange à formação de professores e professoras que se deparam com essas questões. Questões que, se percebidas como uma potencialidade, ajudam na formação de cada um/uma.

Portanto, para retomar o que foi apresentado, este ensaio foi escrito a partir do convite para participar da mesa que trata sobre os temas da política, das práticas e da produção do conhecimento vinculados ao GTT 12 - ID, por ocasião do XVIII Conbrace e do V Conice: Como estamos lidando com a nossa própria experiência pessoal e profissional, quando falamos de inclusão e diferença? Agora, repetindo a mesma pergunta, porém não encontrando as pessoas nos mesmos lugares em que estavam quando o questionamento foi feito no início deste ensaio, estabelecendo uma diferença com a repetição (KOHAN, 2009), embora tendo a convicção que alguma coisa se modificou desde se começou a escrever/ler/escutar este texto, podemos continuar a caminhada, como numa fita de Möbius, já não pensando como se

Pensar a Prática, Goiânia, v. 17, n. 3, p. 893-910, jul./set. 2014 
pensava quando as paisagens aforísticas e poéticas compuseram este caminho, encerro com outra pergunta: Fui transformado ou não por esta experiência?

\title{
POLICIES, PRACTICES AND KNOWLEDGE PRODUCTION IN TWG 12 - INCLUSION AND DIFFERENCE: PARRHESIA, APHORISMS, POETRY
}

\begin{abstract}
This essay aims to dialogue with the experience from the passage by the TWG 12 Inclusion and Difference, of the Brazilian College of Sport Sciences. It presents an analysis of some teaching and academic ways that are possible to be driven. Armed with aphorisms and poetry, this work approaches a parrhesiastic exercise (frank speaking) to promote a debate with the tensions that occur in the referred thematic working group. The tension is understood by its ability to permit a movement that unsettles and which is not permanent.

Keywords: Inclusion and Difference. Parrhesia. Poetry. Aphorisms.

\section{POLÍTICAS, PRÁCTICAS Y PRODUCCIÓN DE CONOCIMIENTO EN GTT 12 - INCLUSIÓN Y DIFERENCIA: PARRESIA, AFORISMOS, POESÍA}

\section{Resumen}

Este ensayo tiene por objeto colaborar con la experiencia que surge del paso a través del GTT 12 - Inclusión y Diferencia del Colegio Brasileño de Ciencias del Deporte. En este sentido, se presenta un análisis de algunos profesores y académicos posibles caminos por recorrer. Armado con aforismos y poesía, este trabajo aborda un ejercicio parresiastico (franco hablando) para tener un debate con las tensiones que se ejecutan en el grupo de trabajo temático. La tensión es comprendida por su potencia mientras la posibilidad que permita un movimiento que perturba y no es permanente.

Palabras-claves: Inclusión y Diferencia. Parresia. Aforismos. Poesía.

\section{Referências}

ABBAGnANO, N. Dicionário de filosofia. São Paulo: Martins Fontes, 2003.

BAUMAN, Z. Modernidade líquida. Rio de Janeiro: Jorge Zahar Editor, 2001.

Pensar a Prática, Goiânia, v. 17, n. 3, p. 893-910, jul./set. 2014 
BACKES, M. Apresentação. In: NIETZSCHE, F. Além do bem e do mal: prelúdio a uma filosofia do futuro. Porto Alegre: L\&PM, 2010.

DELEUZE, G. Diferença e repetição. Rio de Janeiro: Graal, 2006.

FOUCAULT, M. A escrita de si. In: Ditos \& Escritos V: Ética, sexualidade e política. Rio de Janeiro: Forense Universitária, p. 144-162, 2006a.

Graal, 2006b.

História da sexualidade 2: o uso dos prazeres. Rio de Janeiro:

. Theatrum philosophicum. In: Ditos \& Escritos II: Arqueologia da ciência e história dos sistemas de pensamento. Rio de Janeiro: Forense Universitária, 2008.

. Conversa com Michel Foucault. In: Ditos \& Escritos VI: Repensar a política. Rio de Janeiro: Forense Universitária, 2010.

A coragem da verdade: o governo de si e dos outros II: curso no Collège de France (1983-1984). São Paulo: Martins Fontes, 2011.

KOHAN, V. O. Filosofia: o paradoxo de aprender e ensinar. Belo Horizonte: Autêntica, 2009.

O que deve saber um professor deste tempo para alunos deste tempo. Conferência de Abertura da Capacitação Docente 2011/11 (Não publicado). São Leopoldo: Unisinos, 21 fev. 2011.

LARROSA, J. Tecnologias do eu e Educação. In: SILVA, T. T. O sujeito da educação: estudos foucaultianos. Petrópolis: Vozes, p. 35-86, 1994.

Déjame que te cuente: ensaios sobre narrativa y educación. Buenos Aires: Laertes, 2008.

LOPES, M. C. Inclusão escolar: currículo, diferença e identidade. In: ; DAL'IGNA, M. C. In/exclusão: nas tramas da escola. Canoas: Ulbra, p. 11-34, 2007.

; FABRIS, E. H. Inclusão \& educação. (Coleção Temas \& Educação). Belo Horizonte: Autêntica, 2013.

Pensar a Prática, Goiânia, v. 17, n. 3, p. 893-910, jul./set. 2014 
LINHARES, M. A. A produção acadêmico-científica do GTT Inclusão e Diferença nos 15 anos do CBCE. 16 set. 2011. Palestra apresentada no GTT 12 - Inclusão e Diferença no XVII Conbrace e IV Conice (Não publicado). Porto Alegre, 2011.

NIETZSCHE, F. Escritos sobre educação. São Paulo: Loyola, 2009.

REVEL, J. Foucault: conceitos essenciais. São Paulo: Claraluz, 2005.

ROSE, N. Inventando nossos selfs: psicologia, poder e subjetividade. Petrópolis: Vozes, 2011.

SILVA, T. T. Identidade e diferença: impertinências. Educação e Sociedade, v. 23, n. 79, 2002.

Recebido em: 20/05/2014

Revisado em: 22/05/2014

Aprovado em: 04/06/2014

Endereço para correspondência:

mandarino@unisinos.br

Cláudio Marques Mandarino

Universidade do Vale do Rio dos Sinos, Centro de Ciências da Saúde.

Av. Unisinos

Cristo Rei

90470-280 - Sao Leopoldo, RS - Brasil 